\title{
Contralateral cerebellar hypometabolism: a predictor for stroke outcome?
}

Carlo Serrati, Gilles Marchal, Patrice Rioux, Fausto Viader, Marie Christine Petit-Taboué, Phillippe Lochon, Dominique Luet, Jean Michel Derlon, Jean Claude Baron

\begin{abstract}
Contralateral cerebellar hypometabolism (CCH) is a well established remote functional effect of cerebral damage. Because CCH has been reported to be reversible in acute stroke in at least some patients, the value of cerebellar metabolic asymmetry (CbMA; a reflection of the degree of $\mathbf{C C H}$ ) as a predictor of stroke outcome has been assessed. Measurements of cerebellar oxygen consumption were performed by positron emission tomography (PET) in 16 patients within 5-30 hours of onset of their first ever middle cerebral artery territory stroke, and again 13-56 days later in 12 survivors. The neurological state was quantified at the time of each PET study and at day 60 , with both the Mathew and Orgogozo scales. In the early PET study, the CbMAs ranged from around $0 \%$ to nearly $50 \%$ (individually significant at $p<0.05$ in 9/16 patients) but were neither strongly nor consistently correlated with neurological outcome or recovery at day 60 . Similarly, the changes in CbMAs from the early to the late PET study were not correlated with the concomitant neurological evolution. At the late PET study, however, there were excellent positive correlations between CbMAs and both neurological status and size of infarction (assessed by CT in the chronic stage). The correlation with neurological status was explained by the correlation with size of infarction. The poor predictive value of CbMAs in the early PET study may be partly because the cerebral metabolic disturbance might still be evolving at this early stage in some cases. Despite this lack of a strong quantitative link between CbMAs at the early PET study and outcome, the outcome was good in all the patients who did not exhibit significant CCH, suggesting that lack of CCH may predict good outcome in acute middle cerebral artery stroke.
\end{abstract}

$(\mathcal{F}$ Neurol Neurosurg Psychiatry 1994;57:174-179)

Numerous studies of subacute or chronic stroke have established contralateral cerebellar hypometabolism $(\mathrm{CCH})$ as a frequent and sustained remote effect of cerebral infarction, although with debated clinical correlates. ${ }^{1-4}$ In acute stroke, however, $\mathrm{CCH}$ has been only anecdotally reported, ${ }^{25-7}$ and furthermore, its time course is unpredictable, sustained in some patients, but regressive in others.

This last finding suggests that, by analogy with findings on $\mathrm{CCH}$ in other clinical settings, ${ }^{38-10} \mathrm{CCH}$ in acute stroke may partly represent purely functional remote effects of cerebral impairment; thus $\mathrm{CCH}$ could be related to the potential for reversibility of the cerebral metabolic derangement and, in turn, of the clinical deficit. We therefore wondered whether the cerebellar metabolic assymetry (CbMA), as measured in acute stroke, could constitute a readily accessible marker of neurological outcome - an important variable that remains largely unpredictable on clinical grounds. ${ }^{11}$

By means of positron emission tomography (PET), we have measured the CbMA in a homogeneous sample of patients investigated both in the acute $(<30$ hours since clinical onset) and subacute (around one month later) stages of middle cerebral artery infarction to elucidate whether the CbMA at early PET study is predictive of neurological outcome and recovery at two months; and whether the time-course of CbMA parallels the clinical evolution.

\section{Material and methods}

PATIENTS

Patients with acute stroke were selected prospectively according to the criteria: (1) first single, non-haemorragic infarct in the middle cerebral artery territory, confirmed by repeated CT scans; (2) duration since clinical onset $<30$ hours; and (3) age $>18$ years. Exclusion criteria on admission or later were: (1) clouded consciousness or agitation; (2) classical lacunar syndrome; (3) previous or present significant vertebrobasilar disease by clinical or ultrasound (cervical and, whenever possible, transcranial) data; (4) cerebellar damage at admission or follow up CT scan; (5) cardiac, hepatic, or renal failure; (6) recent myocardial infarction; (7) treatment with antivitamin $\mathrm{K}$ compounds; (8) transient ischaemic attack; and (9) technical problems with PET studies (for example movement artifacts, inadequate head positioning). All patients or relatives gave informed consent.

Usual medications (for example, antihypertensives, antiplatelets, antibiotics, heparin) at admission and in the follow up period were allowed, but CNS agents were not. Standard physiotherapy was given to all patients. 
NEUROLOGICAL ASSESSMENT

The neurological deficit was quantified by the same neurologist (GM) with the Mathew and the Orgogozo scales ${ }^{1213}$ immediately before the early and the late PET studies (performed at $<30$ hours and around day 30 respectively) and at day 60 . Both scales are widely used to quantify neurological deficit after middle cerebral artery territory stroke, ${ }^{11}$ and both provide values ranging from 0 to 100 (maximal disability to normal neurological status, respectively); these are differently weighted but highly intercorrelated scales (in this study $\mathrm{p}<0.01$ by both Pearson's and Spearman's rank tests for each of the three clinical evaluations). From these scores, we calculated a recovery index (RI), according to MartinezVilla et $a l,{ }^{14}$ defined as:

$\mathrm{RI}=100$ (day 60 - early PET)/(100-early PET) for improvement, or

$\mathrm{RI}=100$ (day 60-early PET)/early PET for deterioration, where early PET and day 60 represent the neurological scores (either Mathew or Orgogozo) at initial and final evaluations, respectively.

CONTROL SUBJECTS

A control group of 10 subjects (mean age 53 (SD10) years) was taken from a larger sample of strictly healthy volunteers in whom the cerebellar oxygen consumption $\left(\mathrm{CbMRO}_{2}\right)$ was independent of age. ${ }^{15}$

\section{PET PROCEDURE}

We used a standardised procedure described in detail elsewhere. ${ }^{15}$ Briefly, PET scanning was performed with a high resolution four ring PET camera (LETI TTV 003, intrinsic resolution: $5.7 \times 5.7 \times 9 \mathrm{~mm} \mathrm{x,y,z}$ at centre, direct slice). ${ }^{16}$ Subjects were positioned according to a method derived from Fox et $a l^{17}$ based on the glabella-inion (GI) line, which allows definition of the seven PET planes according to the stereotaxic atlas of the human brain. ${ }^{18}$ The studies were performed in dim light, the subject keeping the eyes closed and laying supine. Correction for photon attenuation employed a transmission scan with an external source of germanium68. To measure CBF and $\mathrm{CMRO}_{2}$, we used the ${ }^{15} \mathrm{O}$ steady state method, ${ }^{19-21}$ with successive inhalation of ${ }^{15} \mathrm{O}-\mathrm{CO}_{2},{ }^{15} \mathrm{O}-\mathrm{O}_{2}$ and ${ }^{15} \mathrm{O}-\mathrm{CO}$ for intravascular tracer correction. ${ }^{22-24}$ During each acquisition period, three pairs of arterial blood samples were collected via a thin radial catheter. As well as radioactivity measurements, the arterial blood gases, oxygen saturation, haemoglobin, $\mathrm{pH}$, and packed cell volume were also obtained, allowing calculation of the oxygen arterial content. Finally, the raw PET images were processed pixel by pixel to obtain cerebral blood flow, oxygen extraction fraction, oxygen consumption $\left(\mathrm{CMRO}_{2}\right)$, and blood volume images, according to published methods. ${ }^{19} 2025$

\section{CEREBELLAR REGIONS OF INTEREST}

We used a standardised, objective procedure specially designed to assess $\mathrm{CCH}$ and derived from that of Pantano et al. ${ }^{2}$ On the cerebral blood flow images of the plane $(-4 \mathrm{~mm})$ relative to the GI line, a computer generated $30 \%$ isocontour was first applied to define the cerebellar outer boundaries; then the anterior-posterior median (APM) axis was visually determined, and its position adjusted with respect to the interhemispheric fissure by transfer on to the GI $+56 \mathrm{~mm}$ (corona radiata level) plane. A circular region of interest, $18 \mathrm{~mm}$ radius, was placed in the cerebellar hemisphere ipsilateral to the middle cerebral artery territory infarct, tangentially to both the $30 \%$ isocontour and the APM axis. (In the healthy volunteers, this region of interest was placed on the left cerebellar hemisphere). Then to avoid blood volume artifacts, the region of interest so defined was moved 5 pixels $(5 \mathrm{~mm})$ in the anterior direction, away from the lateral sinus. Subsequently, it was automatically copied over the contralateral hemisphere with respect to the APM axis. Finally, to confirm noninclusion of the venous sinuses, both regions of interest were copied on the corresponding cerebral blood volume images; if necessary, they were then displaced anteriorly by a few pixels.

Once defined, the regions of interest were automatically copied on the corresponding $\mathrm{CMRO}_{2}$ images, and the average $\mathrm{CbMRO}_{2}$ pixel value for the ipsilateral and contralateral sides (right and left for controls) were obtained. From these absolute values, we calculated the percentage cerebellar metabolic asymmetry (CbMA) between contralateral (C) and ipsilateral (I) values ${ }^{2}$ (or between left (L) and right (R) values for controls), according to.the formulae:

$$
\mathrm{CbMA}=100(\mathrm{I}-\mathrm{C}) / \mathrm{I}
$$

and

$$
\mathrm{CbMA}=100(\mathrm{R}-\mathrm{L}) / \mathrm{R}
$$

This formulation results in positive CbMA values in the presence of $\mathrm{CCH}$ (a relative hypometabolism in the cerebellar hemisphere contralateral to cerebral infarction will be reflected as a positive CbMA). The CbMAs of individual patients were assessed for statistical significance against $95 \%$ confidence limits determined in our sample of 10 control subjects. ${ }^{2}$

\section{CT SCAN PROCEDURE}

In all survivors, a plain CT scan (CGR ND1 2000 model) was performed between 30 and 60 days to obtain seven planes matched to the corresponding PET planes with respect to the GI line. By means of this standardised procedure and a BIOCOM 3D image analyser, an index of infarct size was calculated by summing across all affected planes the surface of the hypodense area visually delineated on each plane.

\section{Results}

We studied 16 patients (eight men), mean age 73.4 (SD 7.2) (range 62-88) years. The early PET study was performed five to 30 hours after stroke onset (mean (SD) 13.1 $(6 \cdot 2)$ hours), and the late PET study 13 to 56 
Table 1 Clinical and PET data

\begin{tabular}{|c|c|c|c|c|c|c|c|c|c|c|c|c|c|c|c|}
\hline $\begin{array}{l}\text { Patient no } \\
\text { age/sex }\end{array}$ & $\begin{array}{l}\text { Early PET } \\
\text { (hours) } \dagger\end{array}$ & $\begin{array}{l}\text { Late PET } \\
\text { (days)† }\end{array}$ & $\begin{array}{l}\text { MCA } \\
\text { side }\end{array}$ & Size ${ }^{\text {In }}$ & Topography & $\stackrel{D c}{M S}$ & ${ }^{0}$ os & $M S^{D}$ & 30 OS & $\stackrel{D a}{M S}$ & os & $M S S^{R I}$ & OS & $\begin{array}{l}\% \text { CbMA } \\
\text { (early PET) }\end{array}$ & $\begin{array}{l}\% \text { CbMA } \\
\text { (late PET) }\end{array}$ \\
\hline $\begin{array}{l}\text { 1/86/F } \\
2 / 88 / \mathrm{M} \\
3 / 77 / \mathrm{M} \\
4 / 68 / \mathrm{M} \\
5 / 70 / \mathrm{M} \\
6 / 74 / \mathrm{M} \\
7 / 63 / \mathrm{F} \\
8 / 63 / \mathrm{M} \\
9 / 66 / \mathrm{F} \\
10 / 69 / \mathrm{F} \\
11 / 82 / \mathrm{F} \\
12 / 70 / \mathrm{F} \\
13 / 62 / \mathrm{M} \\
14 / 77 / \mathrm{M} \\
15 / 73 / \mathrm{F} \\
16 / 82 / \mathrm{F}\end{array}$ & $\begin{array}{r}5 \\
6 \\
7 \\
8 \\
8 \\
11 \\
12 \\
13 \\
13 \\
14 \\
16 \\
16 \\
16 \\
16 \\
20 \\
30\end{array}$ & $\begin{array}{l}13 \\
\text { ED } \\
\text { NA } \\
27 \\
15 \\
21 \\
\text { ED } \\
30 \\
23 \\
26 \\
\text { ED } \\
33 \\
55 \\
56 \\
26 \\
20\end{array}$ & 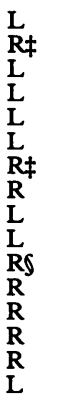 & $\begin{array}{l}\text { Small } \\
\text { Large‡ } \\
\text { Small } \\
\text { Largeł } \\
\text { Small } \\
\text { Small } \\
\text { Largeł } \\
\text { Small } \\
\text { Small } \\
\text { Small } \\
\text { Large§ } \\
\text { Large } \\
\text { Small } \\
\text { Large } \\
\text { Small } \\
\text { Large }\end{array}$ & $\begin{array}{l}\text { F,d } \\
\text { F,T,P,d } \\
\text { F } \\
\text { T,P,d } \\
\text { T,d } \\
\text { d } \\
\text { F,T,P,d } \\
\text { T,d } \\
\text { d } \\
\text { I } \\
\text { F,T,PS } \\
\text { T,P } \\
\text { d } \\
\text { F,T,P,d } \\
\text { d } \\
\text { d }\end{array}$ & $\begin{array}{l}63 \\
57 \\
90 \\
27 \\
68 \\
73 \\
65 \\
66 \\
39 \\
72 \\
23 \\
47 \\
45 \\
54 \\
80 \\
42\end{array}$ & $\begin{array}{l}85 \\
25 \\
95 \\
20 \\
80 \\
79 \\
55 \\
59 \\
55 \\
90 \\
11 \\
20 \\
50 \\
20 \\
90 \\
25\end{array}$ & $\begin{array}{r}100 \\
\text { ED } \\
100 \\
78 \\
70 \\
89 \\
\text { ED } \\
89 \\
72 \\
100 \\
\text { ED } \\
62 \\
93 \\
60 \\
100 \\
47\end{array}$ & $\begin{array}{r}100 \\
\text { ED } \\
100 \\
90 \\
65 \\
85 \\
\text { ED } \\
85 \\
95 \\
100 \\
\text { ED } \\
30 \\
90 \\
30 \\
100 \\
30\end{array}$ & $\begin{array}{r}100 \\
\text { ED } \\
100 \\
94 \\
90 \\
82 \\
\text { ED } \\
92 \\
80 \\
100 \\
\text { ED } \\
65 \\
90 \\
46 \\
100 \\
55\end{array}$ & $\begin{array}{r}100 \\
\text { ED } \\
100 \\
95 \\
90 \\
90 \\
\text { ED } \\
95 \\
90 \\
100 \\
\text { ED } \\
30 \\
100 \\
25 \\
100 \\
30\end{array}$ & $\begin{array}{r}100 \\
\text { ED } \\
100 \\
78 \\
69 \\
60 \\
\text { ED } \\
77 \\
78 \\
100 \\
\text { ED } \\
34 \\
87 \\
-15 \\
100 \\
22\end{array}$ & $\begin{array}{r}100 \\
\text { ED } \\
100 \\
94 \\
50 \\
60 \\
\text { ED } \\
89 \\
78 \\
100 \\
\text { ED } \\
13 \\
100 \\
6 \\
100 \\
7\end{array}$ & $\begin{array}{c}41 \cdot 7^{\star \star} \\
49 \cdot 7^{\star \star} \\
16 \cdot 4^{\star} \\
26 \cdot 2^{\star \star} \\
2 \cdot 1 \\
0 \cdot 6 \\
19 \cdot 0^{\star} \\
14 \cdot 9 \\
7 \cdot 1 \\
-3 \cdot 9 \\
35 \cdot 4^{\star \star} \\
42 \cdot 9^{\star \star} \\
1 \cdot 8 \\
18 \cdot 7^{\star} \\
14 \cdot 9^{-\star} \\
27 \cdot 4^{\star \star}\end{array}$ & $\begin{array}{l}-1 \cdot 8 \\
\text { ED } \\
\text { NA } \\
8 \cdot 9 \\
9 \cdot 8 \\
-4 \cdot 2 \\
\text { ED } \\
20 \cdot 2^{\star \star} \\
15 \cdot 7 \\
6 \cdot 8 \\
\text { ED } \\
29 \cdot 3^{\star \star} \\
-6 \cdot 8 \\
38 \cdot 8^{\star \star} \\
14 \cdot 1 \\
37 \cdot 0^{\star \star}\end{array}$ \\
\hline
\end{tabular}

${ }^{\star} \mathrm{p}<0.05 ;{ }^{\star \star} \mathrm{p}<0.01$ with respect to $95 \%$ confidence limits.

tTime elapsed from clinical onset.

¥Determined as profound hypometabolism by PET.

SDetermined by CT scan at day 3.

ED = early death; MS = Mathew score; OS = Orgogozo score; RI = recovery index; Large $\geqslant 2 \mathrm{~cm}$ diameter; Small $<2 \mathrm{~cm}$ diameter; $R=$ right; $L=$ left; NA = not available; $\mathrm{P}=$ parietal; $\mathrm{F}=$ frontal; $\mathrm{T}=$ temporal; $\mathrm{I}=$ insula; $\mathrm{d}=$ deep $\mathbf{M C A}$ territory; $\mathrm{MCA}=$ middle cerebral artery.

days later (mean (SD) 29 (13) days) in 12 survivors (one survivor declined the late PET study). Table 1 shows the clinical data. Regarding the neurological scores, there was a high intersubject variability in initial scores as well as in both outcome and recovery. Three subjects died early after stroke, at days 3,7 , and 8 (patients 7,2 , and 11 , respectively), all with symptoms of brain herniation (a necropsy was not possible); massive middle cerebral artery infarction was evident in each of these three patients on the basis of the clinical picture, the follow up CT (when available), and the presence of a large area of near zero values on the $\mathrm{CMRO}_{2}$ images. Eight survivors improved, and the disability was essentially stable in the remaining five; but in most cases the neurological scores did not change appreciably from the late PET study to day 60 . The initial scores were not significantly correlated with either outcomes or recovery indices by Pearson's or Spearman's tests.

Table 2 shows the $\mathrm{CbMRO}_{2}$ values at the early and late PET studies, together with the control values. There were significant ( $p<0.01$ by paired $t$ tests) differences between contralateral and ipsilateral $\mathrm{CbMRO}_{2}$ values at both the early and late PET (contralateral < ipsilateral), but none from the early to the late PET study or between patients and controls. Table 1 shows the individual CbMAs, taken to represent the degree of crossed cerebellar hypometabolism as, in agreement with earlier reports, ${ }^{2-4}$ no sig-

Table $2 \mathrm{CbMRO}_{2}$ values in contralateral and ipsilateral cerebellar hemispheres of patients and normal volunteers

\begin{tabular}{|c|c|c|}
\hline & Side & 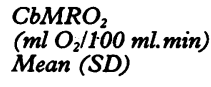 \\
\hline Early PET $(n=16)$ & \multirow{3}{*}{$\begin{array}{l}\text { Ipsilateral } \\
\text { Contralateral } \\
\text { Ipsilateral } \\
\text { Contralateral } \\
\text { Right } \\
\text { Left }\end{array}$} & \multirow{3}{*}{$\begin{array}{l}3.59(1.12) \\
2.84(0.66)^{\star} \\
3.27(0.83) \\
2.68(0.73)^{\star} \\
3.22(0.61) \\
3.22(0.43)\end{array}$} \\
\hline Late PET $(n=12)$ & & \\
\hline Controls $(n=10)$ & & \\
\hline
\end{tabular}

${ }^{\star} \mathrm{p}<0.01 v$ ipsilateral value (2-tailed paired $t$ test) nificant metabolic effect on the ipsilateral cerebellar hemisphere was found (table 2). The distribution of CbMA values at either the early or late PET studies was not significantly different from normality (Kolmogorow-Smirnow test). The mean (SD) CbMA values were $19.7(16.4)$ and $14.0(15 \cdot 2)$ at the early PET and late PET studies, respectively; both were significantly increased compared with controls (mean (SD) $0.3(8.6)$; ( $p<0.02$ for both, unpaired $t$ tests), but were not significantly different from each other (paired $t$ tests). Individually, the CbMAs at the early PET study were significantly increased relative to confidence limits $(>16.0 \%, p<0.05)$ in $9 / 16$ patients; of these nine patients, three still had a significantly raised CbMA at the late PET study, two did not, three had died, and one was not given a late PET. In one patient, the CbMA was significantly increased at the late but not the early PET study (table 1).

The relations between CbMAs and neurological scores were tested with the nonparametric Spearman rank test. Regarding the acute stage (early) PET study, there was no significant correlation between CbMA values and either outcomes at day 60 or RI values, although negative correlations close to the $p=0.10$ level were observed with the RI values (either scale); there was no significant correlation with the clinical scores at either PET study except for the Orgogozo score at day $0(p<0.05)$. By contrast, the CbMAs measured at the late PET study were negatively correlated $(p<0.05)$ with contemporary neurological scores, with final outcomes, and with RIs, regardless of the scale used for assessment (similar, and even more significant negative correlations were obtained with Pearson's linear regression analysis). The negative direction of these relations indicates that the larger the CbMA, the worse the neurological measure. As an illustration, the figure shows the relation between CbMAs at the early and late PET studies on the one hand, and Mathew outcome scores on the other. Although the figure (a) illustrates the 
Figure Cerebellar metabolic asymmetries (CbMAs) measured in (A) the acute (early PET study, 16 patients) and (B) subacute late PET study, 12 survivors) stages against the neurological outcome at day 60 (Mathew scale). At the early study PET, no significant correlation was found by either

Spearman's sign rank test or Pearson's linear

regression. All patients with a $C b M A$ value below about 16\% had a good (>80) outcome, however. For the late PET study, significant correlations were found with both Spearman's ( $r=-0.66$ $p=0.02$ ) and Pearson's (regression line shown, $r=0.80, p<0.001$ ) tests.
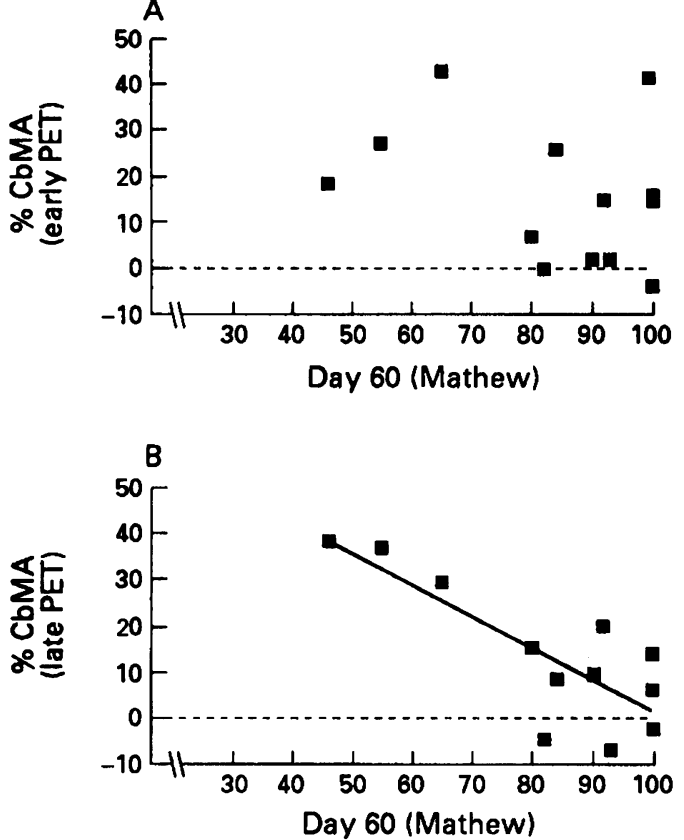

lack of significant quantitative correlation between CbMAs at the early PET study and Mathew score at day 60 , it also indicates that neurological outcome was good (score >80) in all patients in whom the CbMA was below $16.4 \%$ (see also table 1 ), a value similar to our $95 \%$ confidence limit of $16.0 \%$. This finding, which also held for the Orgogozo scale, suggested an alternative analytical approach to our data based on individually categorising each patient according to either significant or non-significant CbMAs at the early PET study on the one hand, and poor (death or scores $<50$ ) or good $(>50)$ neurological outcome or recovery on the other. This analysis confirmed that, for both scales, whereas the occurrence of significant $\mathrm{CCH}$ at the early PET study was not predictive of outcome, its lack was constantly associated with good outcome and recovery.

The CbMAs at the late, but not the early PET study, were significantly positively $(p<0.01)$ correlated with infarct size indexthat is, the larger the infarct the more pronounced the cerebellar asymmetry (data not shown). When this correlation was taken into account, all previously significant correlations between CbMAs at the late PET study and neurological data became non-significant (partial correlation analysis).

Finally, there was no significant correlation between the changes in CbMAs or $\mathrm{CbMRO}_{2}$ values from the early to the late PET study, and the changes in neurological evolution from the early to either the late PET study, or day 60 , or RI values. Likewise, the absolute $\mathrm{CbMRO}_{2}$ values bore no consistent relation with neurological outcome (data not shown), except positive correlations between the contralateral cerebellar metabolic value at the late PET study and outcome at day $60(\mathrm{p}<0.01$ for either scale, Spearman tests).
Discussion

Across the whole patient sample, significant metabolic effects on the contralateral cerebellar hemisphere were already present in the acute stage of middle cerebral artery territory stroke; there was, however, a pronounced and distributed variability in individual CbMAs with values reaching statistical significance in 9/16 (56\%) patients. Although the CbMA did not change significantly from the acute to the subacute stage in the whole sample, its individual time course was highly variable. Equally variable were the initial neurological status and its subsequent evolution, with the first not significantly predictive of the second. Despite these favourable characteristics in terms of sample variance in clinical features and cerebellar metabolic data, there was no consistent or strong link between acute stage CbMA values and neurological outcome or recovery, and no significant relation between changes in CbMA values and in neurological scores from the acute to the subacute stage.

Could methodological issues explain our findings of a weak predictive value of acute stage CbMA? We believe not. The whole PET procedure, from image acquisition to data analysis, was highly controlled and standardised. ${ }^{15}$ Likewise, we prospectively selected middle cerebral artery stroke cases according to rigorous criteria and we used neurological scales that are widely accepted and well adapted to estimate global outcome and recovery after middle cerebral artery territory stroke. ${ }^{11}$ Furthermore, the fact that consistent relations in the biologically expected direction were found between CbMAs in the subacute stage and neurological outcome and recovery at two months would strongly (though indirectly) support the validity of our methodology.

Another potentially confounding issue relates to the topography of the ischaemic area, which could have influenced the magnitude of the contralateral cerebellar hypometabolism. ${ }^{24}$ We selected the patients, however, on the basis of middle cerebral artery territory stroke, excluding lacunar syndromes, anterior or posterior cerebral artery stroke, and thalamic or brain stem infarction. The positive correlation found in our sample between CbMAs in the subacute stage and infarct size would suggest that, with respect to middle cerebral artery territory infarcts, lesion size is an important determinant of $\mathrm{CCH}$.

Could pathophysiological considerations explain our results? Acutely after stroke, for example, cerebellar metabolism could reflect a still unsettled cerebral status, which may comprise not just already irreversibly damaged, but also potentially recoverable tissue ${ }^{26}$; only that part of acute $\mathrm{CCH}$ due to the "potentially recoverable" component, however, could subsequently resolve. Such a mechanism could account for previous reports of transient $\mathrm{CCH}$ registered during episodes of anterior circulation transient ischaemic attack ${ }^{8}$ or temporary balloon occlusion of the internal carotid artery, ${ }^{27}$ and for instances of good neurological outcome 
despite acutely pronounced CbMA in our sample (and, thus for the only weak and inconsistent correlations found between acute stage CbMAs and outcome). In the subacute stage, when the potentially recoverable tissue has turned into either necrosis or functional tissue, closer matching of clinical deficit and CbMAs would be expected, as found here. However attractive such a hypothesis may be, it would need to be tested with a specifically designed experiment.

Another, though not mutually exclusive, hypothesis is that the CbMA reflects the cerebral metabolic state with some time distortion effect-for example, a delay in metabolic expression of transneuronal deafferentation at the level of the contralateral cerebellum. This hypothesis would also help to explain the only weak and inconsistent correlations found here between acute stage CbMA values and contemporary neurological state.

In this study, we assessed the relations between metabolic and outcome values based on a quantitative non-parametric approach, as we were dealing with normally distributed samples. This approach is limited, however, in that it becomes impossible to take into account in the correlations with outcome the three patients who died early after stroke. A closer look at the data presented in table 1 and the figure (a) suggested that qualitative relations existed between acute stage CbMA values and outcome, as all patients with a CbMA equal to or below $16 \cdot 4 \%$ did well in terms of both outcome and recovery; this apparent threshold is strikingly close to the 95\% confidence limit established here at $16.0 \%$. Thus in our sample, a lack of significant acute stage $\mathrm{CCH}$ seemed to consistently predict a good neurological course. If confirmed in a larger scale study, this finding could prove important in early prognosis after middle cerebral artery territory stroke.

By contrast with the lack of significant acute $\mathrm{CCH}$, which indicated a favourable clinical outcome in all instances, its presence was associated with a highly variable subsequent course. Thus although all three patients who died early after stroke exhibited $\mathrm{CCH}$ in the acute stage, three of the six survivors with early $\mathrm{CCH}$ nevertheless had a good outcome (defined here as values $>75$ for both the absolute scores and recovery). This finding is consistent with the already mentioned hypothesis that acute stage $\mathrm{CCH}$ may partly reflect potentially recoverable ischaemic brain tissue.

Finally, we found no significant relation between changes in CbMAs from the acute to the subacute stage and concomitant neurological evolution. This suggests a clinicalmetabolic dissociation that could reflect not only the time distortion effect already alluded to, but also a subsequent compensatory reorganisation of cortical circuits, such as that presumably subtending motor recovery ${ }^{28}$; indeed, this process would induce nonproportionality between neurological state and cerebellar metabolic asymmetry in the subacute stage (and thus account for the lack of statistically significant correlation between subacute CbMAs and neurological outcome after controlling for infarct size). Finally, nonresolving $\mathrm{CCH}$ with irreversible evolution toward transneuronal degeneration, ${ }^{2}$ can be envisaged as a further cause of dissociation between stable or aggravating CbMAs and recovering neurological deficits.

We thank the staff at both the emergency ward and the Neurology Services of the University Hospital in Caen for their continuous support of this project. The help of the technical and secretarial staff of the cyceron PET centre is also gratefully acknowledged.

1 Baron JC, Bousser MG, Comar D, Castaigne P. Crossed cerebellar diaschisis in human supratentorial brain infarction. Trans Am Neurol Assoc 1980;105:459-61.

2 Pantano P, Baron JC, Samson Y, Bousser MG Derouesne C, Comar D. Crossed cerebellar diaschisis. Further studies. Brain 1986;109:677-94.

3 Pappata S, Mazoyer B, Tran-Dinh S, Cambon $H$, Levasseur M, Baron JC. Cortical and cerebella hypometabolic effects of capsular, thalamo-capsular and thalamic stroke: a positron tomography study. Stroke 1990;21:519-24.

4 Tanaka $M$, Kondo $S$, Hirai $S$, Ishiguro $K$, Ishihara $T$, Morimatsu M. Crossed cerebellar diaschisis accompanied by hemiataxia a PET study. $尹$ Neurol Neurosurg Psychiatry 1992;55:121-5.

5 Kushner M, Alavi A, Reivich M, Danu R, Burka A Robinson G. Contralateral cerebellar hypometabolism following cerebral insult: a positron emission tomographic study. Ann Neurol 1984;15:425-34.

6 Kushner M, Kaasik AE, Nencini P, et al. Contralateral cerebellar hypometabolism following cerebral infarction an acute and follow-up study. Neurology 1988;38:147.

7 Meneghetti G, Vorstrup S, Mickey B, Lindewald $\mathbf{H}$ Lassen NA. Crossed cerebellar diaschisis in ischemic stroke: a study of regional blood flow by ${ }^{133} \mathrm{Xe}$ inhalation and single photon emission computerized tomography. f Cereb Blood Flow Metab 1984;4:235-40.

8 Perani D, Gerundini P, Lenzi G L. Cerebral hemispheric and contralateral cerebellar hypoperfusion during transient ischemic attack. $f$ Cereb Blood Flow Metab transient ischem

9 Kurthen M, Reichman K, Linke DB, et al. Crossed cerebellar diaschisis in intracarotid sodium amytal procedures: a SPECT study. Acta Neurol Scand 1990 81:416-22.

10 Yamauchi H, Fukuyama H, Yamaguchi S, et al. Crossed cerebellar hypoperfusion in unilateral major cerebra artery occlusive disorders. F Nucl Med 1992;33: 1637-41.

11 Wade DT. Stroke scales. In: Wade, DT, ed. Measurement in neurological rehabilitation. Oxford: Oxford University Press 1992:291-306.

12 Mathew NT, Meyer JS, Rivera VM. Double blind evaluation of glycerol treatment in acute cerebral infarction. tancet 1972;ii: 1327-33.

13 Orgogozo JM, Capildeo R, Anagnostou CN, et al. Mise au point d'un score neurologique pour l'evaluation clinique point d'un score neurologique pour l'evaluation cliniq
des infarctus sylviens. Presse Med 1983;12:3039-44.

14 Martinez-Villa E, Guillen F, Villenueva JA, et al. Placebo controlled trial of Nimodipin in the treatment of acute controlled trial of Nimodipin in the treatment of acu
ischemic cerebral infarction. Stroke 1990;21:1023-31.

15 Marchal G, Rioux P, Petit-Taboué MC, et al. Regional cerebral oxygen consumption, blood flow, and blood volume in healthy human aging. Arch Neurol 1992; 49:1013-21.

6 Mazoyer B, Trebossen R, Shoukroun C, et al. Physical characteristics of TTV03, a new high spatial resolution time-of-flight positron tomograph. IEEE 1990;37: 778-82.

17 Fox PT, Perlmutter JS, Raichle ME. A stereotactic method of anatomical localization for positron emission tomography. $\mathcal{f}$ Comput Assist Tomogr 1985;9:141-53.

18 Talairach J, Tournoux P. Co-planar stereotaxic atlas of human brain. New York: Thieme Medical Publishers, 1988 .

19 Frackowiak RSJ, Lenzi GL, Jones T, Heather JD. Quantitative measurement of regional blood flow and oxygen in man using ${ }^{15} \mathrm{O}$ and positron emission tomogoxygen in man using ${ }^{15} \mathrm{O}$ and positron emission tomography: theory, procedure and

20 Lebrun-Grandie P, Baron JC, Soussaline F, Loch C Sastre J, Bousser MG. Coupling between regional cerebral blood flow and oxygen consumption in the norma human brain: a study with positron tomography and oxygen 15. Arch Neurol 1983;40:230-6.

1 Lammertsma AA, Jones T, Frackowiak RSJ, Lenzi GL. A theoretical study of the steady state model for measuring regional blood flow and oxygen utilization using oxygen 15. ₹ Comput Assist Tomogr 1981;6:566-73.

22 Lammertsma AA, Jones T. Correction for the presence of intra-vascular oxygen 15 in the steady state technique for measuring regional oxygen extraction ratio in the brain. 1 . Description of the method. $\mathcal{f}$ Cereb Blood Flow Metab 1983;3:416-24. 
23 Lammertsma AA, Baron JC, Jones T. Correction for intravascular activity in the oxygen steady state technique is independent of the regional hematocrit. $\mathcal{F}$ Cereb Blood Flow Metab 1987;7:372-4.

24 Pantano P, Baron JC, Crouzel C, Collard P, Sirou P, Samson $Y$. The ${ }^{15} \mathrm{O}$ continuous-inhalation method: corSamson for ine Med 1985;10:387-91.

25 Sette G, Baron JC, Mazoyer B, Levasseur M, Pappata S, Crouzel C. Local brain haemodynamics and oxygen metabolism in cerebrovascular disease: positron emis- sion tomography. Brain 1989;112:931-51.

26 Heiss WD. Experimental evidence of ischemic thresholds and functional recovery. Stroke 1992;23:1668-72.

27 Brunberg JA, Frey KA, Horton JA, Kuhl DE. Crossed cerebellar diaschisis: occurrence and resolution demonstrated with PET during carotid temporary ballon occlusion. Am 7 Neuroradiol 1992;13:58-61.

28 Jenkins WM, Merzenich MM. Reorganization of neocortical representations after brain injury: a neurophysiological model of the bases of recovery from stroke. Prog Brain Res 1987;71:249-66.
Walter Essex Wynter, Quincke, and lumbar puncture

Though Quincke's name is usually attached to the procedure of lumbar puncture, and rightly so, Walter Wynter, in the same year, devised a comparable if cruder technique.

Walter Essex Wynter (1860-1945) was educated at Epsom College, Surrey, and the Middlesex Hospital. He was the son of a general practitioner, Andrew Wynter, who practised in Chiswick and who edited the British Medical fournal (1855-61). Walter Wynter was FRCP and FRCS, becoming a physician to the Middlesex hospital in 1901.

While a registrar, he reported in The Lancet ${ }^{1}$ four cases of CSF aspiration in meningitis. Case 1 was a boy aged three years, treated in February 1889 with meningitis following an ear infection. Case 2, treated in February 1890, was an 11-year-old girl; case 3 was a two-year-old boy and case 4 was a 13-month-old girl: the last three were all tuberculous.

Wynter made a small incision at L2, cut down to the dura, then inserted a Southey's tube with a rubber drainage to withdraw the infected fluid and reduce the pressure. The procedure afforded but short-lived relief and all four patients died. (Southey's tubes were still in occasional use in 1960, and were used to relieve gross dropsy in the legs which were left dependent overnight to drain litres of oedema fluid into a large bucket.)

Heinrich Irenaeus Quincke (1842-1922) was the son of a physician who practised in Berlin. He was born in Frankfurt-an-der-Oder, read medicine at Berlin, Würzburg and Heidelberg, becoming $M D$ in 1863. Much influenced by his teacher Friederich Frerichs in Berlin, he took the Chairs in Berne and then in Kiel.

$\mathrm{He}$ studied gastrointestinal disorders, advocated surgery for lung abscess, and observed the angiooedema of anaphylaxis, referred to as Quincke's oedema. He observed the pulsation of nailbed capil- laries in aortic regurgitation (Quincke's sign). Studying the CSF in dogs and rabbits, he injected the red sulphide of mercury into the subarachnoid space to demonstrate the flüssigkeit or flow, in 1872. At Kiel he was concerned with the severe headaches associated with hydrocephalus and one month before Wynter's Lancet paper, he reported his first lumbar puncture in "Ueber hydrocephalus", to the Tenth Congress of Internal Medicine at Wiesbaden in April $1891 .^{2}$

Case 1 was a boy of 12 years who died despite six punctures of the ventricles via a trephine, performed in 1888. Case 2 was a boy aged one year nine months, comatose with suspected tubercular meningitis. $\mathrm{He}$ performed three lumbar punctures at three-day intervals in December 1890:

I punctured the subarachnoid space in the lumbar area, passing a very fine cannula $2 \mathrm{~cm}$. deep between the third and fourth lumbar spinal arches and drop by drop I drained a few cubic centimetres of watery fluid...one could see clearly increases with expiration and decrease with inspiration.

The child recovered and the nature of the meningitis or meningism remains uncertain. Case 3 was a man with chronic hydrocephalus aged 25, who suffered from severe headaches. These were relieved by lumbar puncture, but again the aetiology was not established By 21 September, 1891 his paper $^{3}$ included lumbar puncture in five children and five adults. He acknowledged Wynter's work.

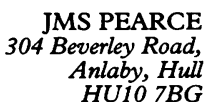

1 Wynter WE. Four cases of tubercular meningitis in which paracentesis was performed for the relief of fluid pressure. Lancet 1891;1:981-2.

2 Quincke HI. Ueber hydrocephalus. Verhandlung des Congress Innere Medizin $(X), 1891 ; 321-39$.

3 Quincke HI. Die lumbalpunction des Hydrocephalus. Berl Klin Wochenschr 1891;28:929-33. 